\title{
A new synthesis of triazolo[4,5-g]quinolines and unexpected ring reduced products by treatment with hydrazine hydrate
}

\author{
Antonio Carta* and Giuseppe Paglietti \\ Dipartimento Farmaco Chimico Tossicologico,University of Sassari, \\ Via Muroni, 23, 07100 Sassari ,Italy \\ E-mail: acarta@uniss.it
}
Dedicated to Professor Vincenzo Tortorella in the occasion of his "Fuori Ruolo" status (received 05 Nov 03; accepted 04 Feb 04; published on the web 11 Feb 04)

\begin{abstract}
A new synthesis of the linear heterocycle 4-chloro- $1 H$-triazolo[4,5-g]quinoline by reduction of the novel compound 4-chloro- $1 H$-triazolo[4,5-g]quinoline-1-oxide is reported. Treatment of the latter with hydrazine hydrate in ethanol in a sealed steel vessel in the presence or not of palladised charcoal, under various conditions of both time and temperature, afforded some derivatives of both ring reduction and ring construction.
\end{abstract}

Keywords: Triazolo[4,5-g]quinolines, dihydro and tetrahydro triazolo[ $[4,5-g]$ quinolines

\section{Introduction}

Triazolo[4,5-f]quinoline (1) is a tricyclic system which was first reported by German authors in $1934^{1}$, but not mentioned in Chemical Abstracts. Triazolo[4,5-h]quinoline (2) appeared as a side product during the preparation of 7,8-triazoloquinolin-5-arsonic acid by H. Slater ${ }^{2}$ in 1932, while triazolo[4,5-g]quinoline (3) was instead described by us for the first time in $2000^{3}$. More recently, compound 2 has been obtained by Italian authors through an alternative route ${ }^{4}$.

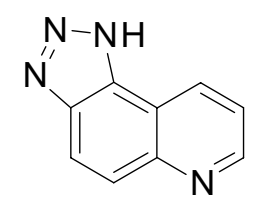

1

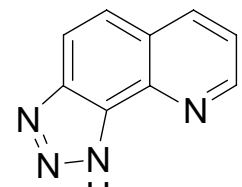

2<smiles>c1cnc2cc3[nH]nnc3cc2c1</smiles>

3 
It is evident from this that no much chemistry related to these tricyclic systems was developed so far. Some time ago, we had focused our attention to this backbone that, owing to its planarity, could act as a good substrate in order to prepare compounds of pharmacological interest either as antibacterial or anticancer and antiviral agents.

In this context we have described several triazolo[4,5-f]- and [4,5-h]quinoline-carboxylic acids as antimicrobial analogues of oxolinic acid $^{5,6}$ as well as the anticancer activity of some 9aminoalkylamino triazolo[4,5-f]quinolines. ${ }^{7}$

As contribution from our laboratory for the knowledge of the chemistry of this type of heterocycles, now we present a new synthesis of the linear triazolo[4,5-g]quinoline of particular interest for us because of its larger extension in comparison with the angular isomers and more suitable to build up novel compounds endowed with potential intercalating properties. In addition we report some aspects of the reactivity of this heterocycle.

\section{Results and Discussion}

\section{Chemistry}

We have explored the synthetic pathway of Scheme 1 that starting from the known compound $\mathbf{4}^{3}$ might afford the previously described compounds $\mathbf{3}$ and $\mathbf{6}$ in better yields opening a chance for their further modifications.

Then, compound $\mathbf{4}$ was submitted to reaction with a large excess of hydrazine hydrate in ethanol to give the N-oxide 5 in $90 \%$ yield. This was an improvement in comparison with the previously described reaction carried out at higher temperature that produced only the reduction of the nitro group. ${ }^{3}$ However, the successive step to obtain $\mathbf{3}$ and $\mathbf{6}$ according to our wishes was partially successful but the attempts at the removal of the N-oxide group led to the isolation of very interesting derivatives. In fact, when we carried out the reduction of $\mathbf{5}$ with hydrazine hydrate in ethanol in the presence of palladised charcoal under various conditions of both time and temperature, we were able to observe that formation of the compounds $\mathbf{8}, \mathbf{9}$ and $\mathbf{1 0}$ was mainly dependent on the time/temperature ratio. Thus, at $100^{\circ} \mathrm{C}$ for $15 \mathrm{~h}$ we obtained compound 8 in $44 \%$ yield. As the temperature was raised up to $140^{\circ} \mathrm{C}$ for the same reaction time, compound 10 was instead formed in $58 \%$ yield together with 8 in $20 \%$ yield. At temperature of $140^{\circ} \mathrm{C}$ for shorter time (12 h) a mixture of compounds 8, 9 and $\mathbf{1 0}$ was obtained in a ratio of approximately 1:2:0.5 respectively. In conclusion we can say that at higher temperature the benzene portion is more susceptible to reduction to the dihydro stage, whereas the pyridine ring may be reduced in higher yield lowering the temperature. Each compound was unambiguously identified by its mass and ${ }^{1} \mathrm{H},{ }^{13} \mathrm{C}-\mathrm{NMR}$ spectrum. In particular, for compounds $\mathbf{9}$ and $\mathbf{1 0}$ the resonance of the $\mathrm{CH}_{2}$ at positions 4 and 9 as separate singlets as well as that of the C-4 and C-9 protons in compound 8 was of diagnostic significance, the chemical shift of which being affected by the electronegative effects of neighbouring atoms. These results were quite surprising since it is well known that pyridine ring of the quinoline easily undergoes reduction rather than the benzene 
counterpart using different conditions ${ }^{8}$ and this could account for the isolation of 8 to a larger extent (44\%) when operating at lower temperature. Conversely, the reduction of the benzene ring of either benzotriazole or quinoline requests more drastic conditions. ${ }^{8}$ An explanation for this result could lie on the feature of this linear tricyclic structure, very similar in some respects to anthracene, which is known to undergo catalytic hydrogenation to dihydro and tetrahydro stage under mild conditions. ${ }^{8}$<smiles>Clc1c2ncccc2cc2nn[nH]c12</smiles>

(6) $(21 \%)$<smiles>O=[N+]([O-])c1cc2cccnc2c(Cl)c1Cl</smiles>

(4)

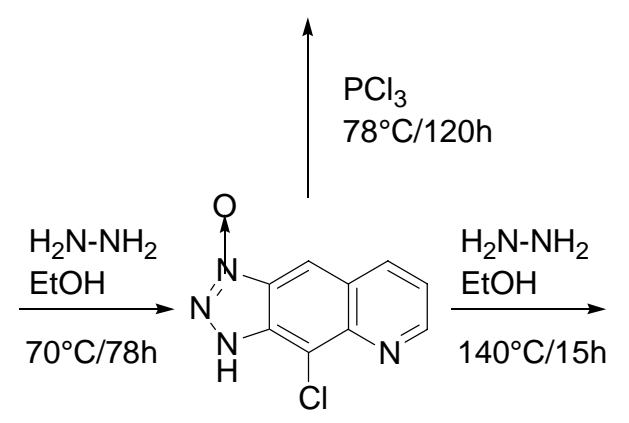

(5) $(90 \%)$

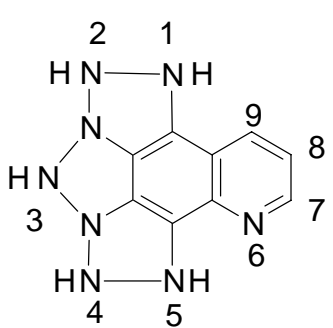

(7) $(25 \%)$

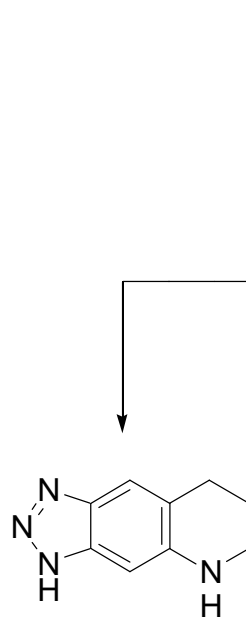

(8)

(44\%) (i) (22\%) (ii) (20\%) (iii)
$10 \% \mathrm{Pd} / \mathrm{C}$ $\mathrm{H}_{2} \mathrm{~N}-\mathrm{NH}_{2} / \mathrm{EtOH}$

(i)

(ii)

(iii)

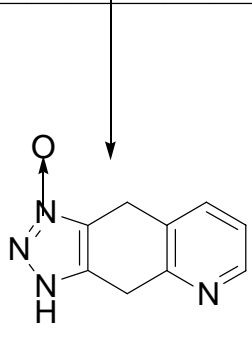

(9)

(45\%) (ii)
(10)

(13\%) (ii) (58\%) (iii)

Scheme 1. Preparation of compounds 5-10. Conditions: (i) $100{ }^{\circ} \mathrm{C} / 15 \mathrm{~h}$; (ii) $140{ }^{\circ} \mathrm{C} / 12 \mathrm{~h}$; (iii) $140^{\circ} \mathrm{C} / 15 \mathrm{~h}$.

The nature of the compounds obtained during this type of hydrogenation clearly indicates that displacement of chlorine at position 4 is the first step of the reduction of 5 under the 
conditions examined, followed by a Birch type reduction of the benzene moiety to dihydro stage 9 and successive removal of oxygen 10. The stability of the isolated compounds seems to exclude that a disproportionation between the dihydro and the tetrahydro quinolines may occur. Compound 5 was converted into 6 by treatment with $\mathrm{PCl}_{3}$ in no satisfactory yield (20\%). Another observation to point out was that when we run the reaction at $140^{\circ} \mathrm{C}$ with an excess of hydrazine hydrate in the absence of the catalyst, compound 5 gave the pentacycle derivative (7) that represents a typical case of reactivity of this ring. In our opinion a mechanism for its formation can be put forward considering that hydrazine in the absence of the catalyst behaves as strong base prior to decompose to hydrogen and nitrogen and an easy attack on the two electrophilic centers of 5 takes place to build up symmetrical dihydrotriazole rings (Scheme 2).

Confirmation of the structure of 7 came from the analytical data (ir, uv and nmr spectra) and mainly by the examination of its fragmentation in LC/Mass (vide infra) where from the peak mass $(229,100 \%, M+1)$ we were able to detect the gradual loss of nitrogen and hydrogen up to quinoline mass peak (129), no other fragments being further observed below this value. In the end we have also examined the reactivity of both $\mathbf{5}$ and $\mathbf{6}$ towards the electrophilic reagents as nitric acid, acetic anhydride and chloroacetonitrile.

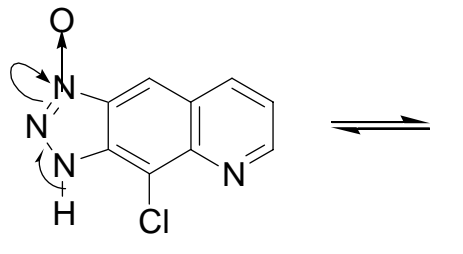

(5)
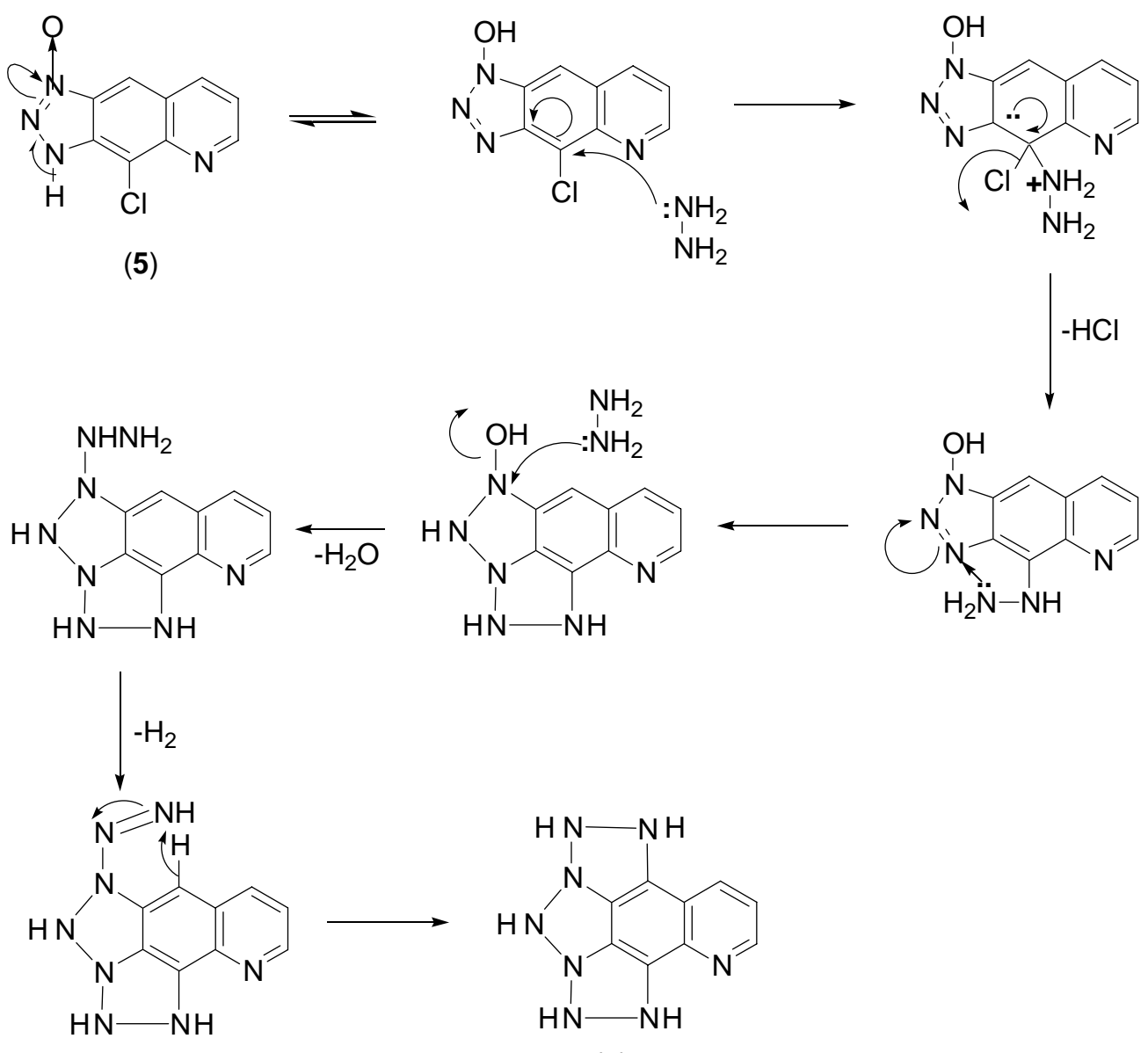

(7)

Scheme 2. Hypothesis of mechanism for the synthesis of the compound 7. 
On nitration either N-oxide derivative 5 (Scheme 3) or compound 6 (Scheme 4) yielded the corresponding 9-nitro derivatives 11 and 12 recording the better yields for 12, this would indicate that the presence of $\mathrm{N}$-oxide makes this position less nucleophilic. In the case of reaction with acetic anhydride only compound 6 gave the 3-acetyl derivative 13 in 69\% yield (Scheme 4). The exact position of the acetyl group was deduced from ${ }^{1} \mathrm{H}-\mathrm{NMR}$ NOE experiments. In fact, irradiation of $\mathrm{CH}_{3}$ signal at $\delta 3.07$ caused a NOE between this and the singlet located at $\delta 8.70$ of the H-9, thus showing the position of acetylation.

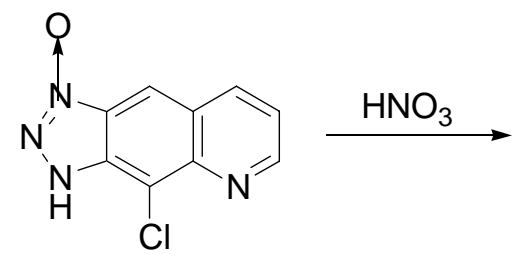

(5)<smiles></smiles>

(11)

Scheme 3. Preparation of the compound 11.

The attempts at alkylation of the triazole moiety was carried out in alkaline medium in order to obtain the corresponding triazole anion whose negative charge that can be stabilised by resonance on the three nitrogen atoms causing the opportunity to give three alkylated isomers.<smiles>O=[N+]([O-])c1cnc2ccc([N+](=O)[O-])c(Cl)c2c1</smiles>

(12)<smiles>Clc1c2ncccc2cc2nn[nH]c12</smiles>

(6)<smiles>CC(=O)n1nnc2c(Cl)c3ncccc3cc21</smiles>

(13)<smiles></smiles>

Scheme 4. Preparation of the compounds 12-15.

However, this reaction was successful only in the case of $\mathbf{6}$ that gave the isomers $\mathbf{1 4}$ and $\mathbf{1 5}$. Confirmation of their structures came from the examination of ${ }^{13} \mathrm{C}-\mathrm{NMR}$ spectra that 
unambiguously assigned the chemical shift of the $\mathrm{CH}_{2}$ carbons of the side chain to 1 or 3 ring substituted derivatives according to our previous described observations. ${ }^{9}$ In addition, irradiation of the $\mathrm{CH}_{2}$ signal at $\delta .6 .39$ of the compound 15 caused a NOE between this and the H-9 singlet located at $\delta 8.58$, thus confirming the exact position of alkylation. In the case of 14, as expected, no NOE was observed between the protons of the $\mathrm{CH}_{2}$ group and the distant $\mathrm{H}-9$ proton.

\section{Conclusions}

In the light of the above results the heterocyclic system of triazolo[4,5-g]quinoline $\mathrm{N}$-oxide (5) demonstrated peculiar properties which allowed to obtain the reduced triazolo[4,5-g]quinolines (8) and (10) and its N-oxide 9 otherwise more difficult to prepare by alternative procedures. In addition formation of pentacycle derivative 7 seems to open a new route for obtaining more complicated heterocycles through an accessible intermediate 5.

\section{Experimental Section}

General Procedures. Melting points were determined in open capillaries in a Digital Electrothermal IA9100 melting point apparatus and are uncorrected. Column chromatography was performed on silica gel (Merck 60, 70-230 mesh). The $R_{\mathrm{f}}$ values were measured on aluminium backed TLC plates of silica gel 60 F254 (Merck, $0.2 \mathrm{~mm}$ ) with the indicated eluent. IR spectra were recorded as nujol mulls on a Perkin Elmer 781 spectrophotometer and are expressed in $\mathrm{cm}^{-1}$. UV spectra are qualitative and were recorded in $\mathrm{nm}$ for ethanol solution with a Perkin-Elmer Lambda 5 spectrophotometer. NMR spectra were recorded on a Varian XL 200 spectrometer. Chemical shifts ( $\delta$ in ppm) are given from internal $\mathrm{CHCl}_{3}$ (7.26) for ${ }^{1} \mathrm{H} \mathrm{NMR}$, ${ }^{13} \mathrm{CDCl}_{3}$ (77.0) for ${ }^{13} \mathrm{C} \mathrm{NMR}$. Coupling constants $\left(\mathrm{J}\right.$ in $\mathrm{Hz}$ ) are accurate to $\pm 0.2 \mathrm{~Hz}$ for ${ }^{1} \mathrm{H}$ and \pm $0.6 \mathrm{~Hz}$ for ${ }^{13} \mathrm{C}$. MS spectra were performed on a combined HP 5790 (GC)-HP 5970 (MS) apparatus or with a combined Liquid Chromatograph-Agilent 1100 series Mass Selective Detector (MSD).

4-Chloro-1H-triazolo[4,5-g]quinoline-1-oxide (5). A mixture of compound 4 (3 g, $12.3 \mathrm{mmol}$ ), dissolved in ethanol $(100 \mathrm{~mL})$, and a large excess of hydrazine hydrate $(7 \mathrm{~mL}, 144 \mathrm{mmol})$ was heated in a sealed steel vessel at $70^{\circ}$ for $86 \mathrm{~h}$. On cooling, the formed precipitate was collected, washed with ethanol and eventually dried in a oven to give compound 5 as a solid $(2.60 \mathrm{~g}, 90 \%$ yield) $\mathrm{mp} .>300^{\circ} \mathrm{C}$. IR $\left(\mathrm{cm}^{-1}\right): 3276,1653,1622$. UV-Vis $(\mathrm{nm}): \lambda_{\max } 201,240,306,320,429 .{ }^{1} \mathrm{H}-$ NMR (DMSO-d $\left.)_{6}\right): \delta 9.10(\mathrm{~d}, 1 \mathrm{H}, J=3.8 \mathrm{~Hz}, \mathrm{H}-6), 8.68(\mathrm{~d}, 1 \mathrm{H}, J=8.8 \mathrm{~Hz}, \mathrm{H}-8), 8.46$ (s, 1H, H9), 7.65 (dd, $1 \mathrm{H}, J=8.8$ and $3.8 \mathrm{~Hz}, \mathrm{H}-7)$. LC/MS: $221(\mathrm{M}+\mathrm{H})$; Anal. Calcd. for $\mathrm{C}_{9} \mathrm{H}_{5} \mathrm{~N}_{4} \mathrm{OCl}$ : C, 49.00; H, 2.28; N, 25.40; Cl, 16.07. Found C, 48.78; H, 2.52; N, 25.04; Cl, 16.36. 
4-Chloro-1H-triazolo[4,5-g]quinoline (6). Compound 5 ( $1 \mathrm{~g}, 4.5 \mathrm{mmol}$ ) was suspended in $\mathrm{PCl}_{3}$ $(25 \mathrm{~mL})$ and heated under reflux with continuous magnetic stirring for $144 \mathrm{~h}$. After then an insoluble residue was collected and washed with ether. The semisolid material was mixed with silica gel and chromatographed on silica gel column eluting with a mixture of ether ethanol in 8:2 ratio. The first fractions, after evaporation, gave a solid 6 ( $0.20 \mathrm{~g}, 21.7 \%$ yield $)$, mp 283$284{ }^{\circ} \mathrm{C}$ from acetone; identical with the authentic specimen previously described. ${ }^{3}$

For further elution of the column with a mixture 1:1 ratio of diethyl ether- ethanol we recovered $0.30 \mathrm{~g}$ of starting material 5 .

\section{Attempts at reduction of 5 with hydrazine hydrate in the presence of catalyst Method A}

(i) Compound 5 (1 g, $4.5 \mathrm{mmol})$ was suspended in ethanol $(100 \mathrm{~mL})$, added of hydrazine hydrate ( $7 \mathrm{~mL}, 144 \mathrm{mmol})$ and $10 \%$ Palladised charcoal $(0.2 \mathrm{~g})$. The mixture was heated under stirring in a sealed steel vessel at $140^{\circ} \mathrm{C}$ for $12 \mathrm{~h}$. On cooling, the catalyst was removed by filtration and the mother liquors were evaporated under reduced pressure. The crude solid obtained was then chromatographed on silica gel column eluting with a mixture of:

(a) diethyl ether/ethanol (9:1 ratio) to give after evaporation of the identical fractions, monitored by tlc, 5,6,7,8-tetrahydro-1H-triazolo[4,5-g]quinoline (8) (0.17 g, 22\% yield), mp 164- $166^{\circ} \mathrm{C}$ from ethanol, TLC (diethyl ether ethanol 8:2): $\mathrm{R}_{\mathrm{f}} 0.78$. IR ( $\left.\mathrm{cm}^{-1}\right): 3399,1633$. UV (nm): $\lambda_{\max } 196,219,320 .{ }^{1} \mathrm{H}-\mathrm{NMR}\left(\mathrm{DMSO}_{6}\right): \delta 14.65$ (br s, $\left.1 \mathrm{H}, \mathrm{NH}\right), 7.43$ (s, 1H, H-9), 6.52 (s, 1H, H-4), 3.24 (t, 2H, $\left.J=5.6 \mathrm{~Hz}, \mathrm{C}_{6}-\mathrm{H}_{2}\right), 2.83$ (t, 2H, $\left.J=5.6 \mathrm{~Hz}, \mathrm{C}_{8}-\mathrm{H}_{2}\right), 1.80$ (m, 2H, C $7^{-}$ $\left.\mathrm{H}_{2}\right) .{ }^{13} \mathrm{C}-\mathrm{NMR}\left(\mathrm{DMSO}_{6}\right.$ ): $\delta 145.54$ (s), 136.92 (s), 134.38 (s), 121.60 (d), 116.57 (d), 88.58 (s), 40.88 (t), 27.89 (t), 21.43 (t). MS M/Z $174\left(\mathrm{M}^{+}\right)$; Anal. Calcd. for $\mathrm{C}_{9} \mathrm{H}_{10} \mathrm{~N}_{4}$ : C, 62.05; H, 5.79; N, 32.16. Found C, 62.36; H, 5.54; N, 32.01;

(b) diethyl ether/ethanol (6:4 ratio) to give after evaporation of the identical fractions, monitored by tlc, 4,9-dihydro-1H-triazolo[4,5-g]quinoline (10) (0.10 g, 13\% yield), mp 226$228^{\circ} \mathrm{C}$ (decom), TLC (diethyl ether ethanol 8:2): $\mathrm{R}_{\mathrm{f}}$ 0.48. IR $\left(\mathrm{cm}^{-1}\right): 3509,2717,2665,1637$, 1616. UV (nm): $\lambda_{\max } 218,321 .{ }^{1} \mathrm{H}-\mathrm{NMR}\left(\mathrm{DMSO}_{6} \mathrm{~d}_{6}\right): \delta 8.82(\mathrm{~d}, 1 \mathrm{H}, J=5.2 \mathrm{~Hz}, \mathrm{H}-6), 8.50(\mathrm{~d}$, $1 \mathrm{H}, J=7.6 \mathrm{~Hz}, \mathrm{H}-8), 7.92(\mathrm{dd}, 1 \mathrm{H}, J=7.6$ and $5.2 \mathrm{~Hz}, \mathrm{H}-7), 4.50\left(\mathrm{~s}, 2 \mathrm{H}, \mathrm{C}_{4}-\mathrm{H}_{2}\right), 4.32(\mathrm{~s}, 2 \mathrm{H}$, $\mathrm{C}_{9}-\mathrm{H}_{2}$ ). ${ }^{13} \mathrm{C}-\mathrm{NMR}\left(\mathrm{DMSO}_{\mathrm{d}}\right.$ ): $\delta 149.17$ (s), 146.78 (d), 141.04 (d), 137.04 (s), 136.47 (s), 134.03 (s), 124.80 (d), 26.20 (t), 25.04 (t). MS M/Z $172\left(\mathrm{M}^{+}\right)$; Anal. Calcd. for $\mathrm{C}_{9} \mathrm{H}_{8} \mathrm{~N}_{4}: \mathrm{C}, 62.78$; H, 4.68; N, 32.57. Found C, 63.04; H, 4.49; N, 32.29;

(c) diethyl ether/ethanol (1:1 ratio) to give after evaporation of the identical fractions, monitored by tlc, 4,9-dihydro-1H-triazolo[4,5-g]quinoline-1-oxide (9) (0.38 g, 45\% yield), mp $>300^{\circ} \mathrm{C}$, TLC (diethyl ether ethanol 8:2): $\mathrm{R}_{\mathrm{f}} 0.15$. IR $\left(\mathrm{cm}^{-1}\right): 3400,2750,2670,1652$. UV (nm): $\lambda_{\max } 198,233 .{ }^{1} \mathrm{H}-\mathrm{NMR}\left(\mathrm{DMSO}_{-} \mathrm{d}_{6}\right): \delta 8.41(\mathrm{~d}, 1 \mathrm{H}, J=4.8 \mathrm{~Hz}, \mathrm{H}-6), 7.68(\mathrm{~d}, 1 \mathrm{H}, J=7.0 \mathrm{~Hz}, \mathrm{H}-$ 8), $7.23(\mathrm{dd}, 1 \mathrm{H}, J=7.0$ and $4.8 \mathrm{~Hz}, \mathrm{H}-7), 3.94\left(\mathrm{~s}, 2 \mathrm{H}, \mathrm{C}_{4}-\mathrm{H}_{2}\right), 3.76\left(\mathrm{~s}, 2 \mathrm{H}, \mathrm{C}_{9}-\mathrm{H}_{2}\right) .{ }^{13} \mathrm{C}-\mathrm{NMR}$ $\left(\mathrm{D}_{2} \mathrm{O}\right): \delta 153.70$ (s), 148.59 (d), 141.97 (d), 139.93 (s), 130.25 (s), 124.84 (d), 123.52 (s), 31.54 (t), $25.73(\mathrm{t})$. LC/MS: $189(\mathrm{M}+\mathrm{H}), 211(\mathrm{M}+\mathrm{Na}), 227(\mathrm{M}+\mathrm{K})$; Anal. Calcd. for $\mathrm{C}_{9} \mathrm{H}_{8} \mathrm{~N}_{4} \mathrm{O}: \mathrm{C}$, 57.44; H, 4.29; N, 29.80. Found C, 57.81; H, 4.07; N, 30.19. 
(ii) Compound 5 ( $1 \mathrm{~g}, 4.5 \mathrm{mmol})$ was suspended in ethanol $(100 \mathrm{~mL})$, added of hydrazine hydrate $(7 \mathrm{~mL}, 144 \mathrm{mmol})$ and $10 \%$ Palladised charcoal $(0.2 \mathrm{~g})$. The mixture was heated under stirring in a sealed steel vessel at $100^{\circ} \mathrm{C}$ for $15 \mathrm{~h}$. On cooling, the catalyst was removed by filtration and the mother liquors were evaporated under reduced pressure. The crude solid obtained was then chromatographed on silica gel column eluting with a mixture of diethyl ether/ethanol (9:1 ratio) to give after evaporation of the identical fractions monitored by tlc 5,6,7,8-tetrahydro-1Htriazolo[4,5-g]quinoline (8) (0.34 g, 44\% yield), identical with an authentic specimen as above. Method B

(iii) Compound 5 ( $1 \mathrm{~g}, 4.5 \mathrm{mmol})$ was suspended in ethanol $(100 \mathrm{~mL})$, added of hydrazine hydrate $(7 \mathrm{~mL}, 144 \mathrm{mmol})$ and $10 \%$ Palladised charcoal $(0.2 \mathrm{~g})$. The mixture was heated under stirring in a sealed steel vessel at $140^{\circ} \mathrm{C}$ for $15 \mathrm{~h}$. On cooling the catalyst was removed by filtration and the mother liquors were evaporated under reduced pressure. The crude solid obtained was then chromatographed on silica gel column eluting with a mixture of :

(a) diethyl ether/ethanol (9:1 ratio) to give after evaporation of the identical fractions, monitored by tlc, 5,6,7,8-tetrahydro-1H-triazolo[4,5-g]quinoline (8) (0.15 g, 20\% yield), identical with an authentic specimen as above;

(b) diethyl ether/ethanol (6:4 ratio) to give after evaporation of the identical fractions, monitored by tlc, 4,9-dihydro-1H-triazolo[4,5-g]quinoline (10) (0.45 g, 58\% yield), identical with an authentic specimen as above.

\section{Attempts at reduction of $\mathbf{5}$ with hydrazine hydrate in the absence of catalyst}

A mixture of compound 5 ( $1 \mathrm{~g}, 4.5 \mathrm{mmol})$, suspended in ethanol $(100 \mathrm{~mL})$, and added of hydrazine hydrate $(7 \mathrm{~mL}, 144 \mathrm{mmol})$ was heated under stirring in a sealed steel vessel at $140^{\circ} \mathrm{C}$ for $15 \mathrm{~h}$. On cooling a solid was collected and thoroughly washed with ethanol to give compound $7(0.25 \mathrm{~g}, 24.3 \%$ yield $), \mathrm{mp}>300^{\circ} \mathrm{C}$. IR $\left(\mathrm{cm}^{-1}\right): 3362,3280,3187,1630$. UV (nm): $\lambda_{\max } 197$, 259, 334. ${ }^{1} \mathrm{H}-\mathrm{NMR}\left(\mathrm{DMSO}-\mathrm{d}_{6}\right.$ ): $\delta 8.90-8.30$ (br m, 5H, $5 \mathrm{NH}$, exchanges with $\mathrm{D}_{2} \mathrm{O}$ ), 8.48-8.44 (m, 2H, H-7 + H-9), 7.26 (dd, $1 \mathrm{H}, J=7.8$ and $4.6 \mathrm{~Hz}, \mathrm{H}-8) .{ }^{13} \mathrm{C}-\mathrm{NMR}\left(\mathrm{DMSO}_{6}\right)$ ): $\delta 148.01$ (s), 147.47 (d), 138.00 (s), 136.55 (s), 131.26 (d), 130.48 (s), 128.67 (s), 127.75 (s), 121.32 (d). LC/MS: 267 (5.3\%) (M +K), 251 (28.8\%) (M +Na), 229 (100\%) (M +H), $213(5.2 \%)(\mathrm{M}-\mathrm{NH})$, $185(3.3 \%)(\mathrm{M}-3 \mathrm{~N}-\mathrm{H}), 172(10.8 \%)(\mathrm{M}-4 \mathrm{~N}), 156(7.3 \%)(\mathrm{M}-5 \mathrm{~N}-2 \mathrm{H}), 144(8.1 \%)(\mathrm{M}-6 \mathrm{~N})$, 129 (6.2\%) (Quinoline ${ }^{+}$). Anal. Calcd. for $\mathrm{C}_{9} \mathrm{H}_{10} \mathrm{~N}_{8}+\left(1 \mathrm{H}_{2} \mathrm{O}+1 / 2 \mathrm{~N}_{2} \mathrm{H}_{4}\right): \mathrm{C}, 41.22 ; \mathrm{H}, 4.61 ; \mathrm{N}$, 48.07. Found C, 40.90; H, 4.69; N, 48.07;

4-Chloro-9-nitro-1H-triazolo[4,5-g]quinoline-1-oxide (11). To compound 5 (0.8 g, 3.6 mmol), dissolved in concd sulphuric acid $(4 \mathrm{~mL})$, was added dropwise at room temperature a solution of potassium nitrate $(1.2 \mathrm{~g}, 12 \mathrm{mmol})$ in concd sulphuric acid $(3 \mathrm{~mL})$. Then the temperature was raised up to $50^{\circ} \mathrm{C}$ for $3 \mathrm{~h}$ under continuous stirring. The mixture was poured on crushed ice and water $(50 \mathrm{~mL})$ and made alkaline with $30 \%$ aqueous ammonia solution. The formed solid was collected, washed with water and eventually dried in an oven to give compound $11(0.20 \mathrm{~g}, 21 \%$ yield), $\mathrm{mp}>300^{\circ} \mathrm{C}$. IR $\left(\mathrm{cm}^{-1}\right): 3080,1618,1603$. UV-Vis (nm): $\lambda_{\max } 204,229,246,383,407$, 452. ${ }^{1} \mathrm{H}-\mathrm{NMR}\left(\mathrm{DMSO}_{-}\right.$): $\delta 9.13(\mathrm{~d}, 1 \mathrm{H}, J=3.4 \mathrm{~Hz}, \mathrm{H}-6), 8.75(\mathrm{~d}, 1 \mathrm{H}, J=8.6 \mathrm{~Hz}, \mathrm{H}-8), 7.78$ 
(dd, $1 \mathrm{H}, J=8.6$ and $3.4 \mathrm{~Hz}, \mathrm{H}-7)$. LC/MS: $266(\mathrm{M}+\mathrm{H})$; Anal. Calcd. for $\mathrm{C}_{9} \mathrm{H}_{4} \mathrm{~N}_{5} \mathrm{O}_{3} \mathrm{Cl}$ : C, 40.76; H, 1.52; N, 26.37; Cl, 13.35. Found C, 40.41; H, 1.67; N, 26.04; Cl, 13.11.

4-Chloro-9-nitro-1H-triazolo[4,5-g]quinoline (12). To compound 6 (0.8 g, 3.9 mmol), dissolved in concd sulphuric acid $(4 \mathrm{~mL})$, was added dropwise at room temperature a solution of potassium nitrate $(1.2 \mathrm{~g}, 12 \mathrm{mmol})$ in concd sulphuric acid $(3 \mathrm{~mL})$. Then the temperature was raised up to $50^{\circ} \mathrm{C}$ for $3 \mathrm{~h}$ under continuous stirring. The mixture was poured on crushed ice and water $(50 \mathrm{~mL})$. The formed solid was collected, washed with water and eventually dried in an oven to give compound 12 (0.54 g, 55\% yield), $\mathrm{mp}>300^{\circ} \mathrm{C}$. IR $\left(\mathrm{cm}^{-1}\right)$ : 3472,1659 . UV (nm): $\lambda_{\max } 206,229,303,317,370 .{ }^{1} \mathrm{H}-\mathrm{NMR}\left(\mathrm{DMSO}_{\mathrm{d}}\right): \delta 9.11(\mathrm{~d}, 1 \mathrm{H}, J=3.6 \mathrm{~Hz}, \mathrm{H}-6), 8.69$ (d, 1H, $J=8.4 \mathrm{~Hz}, \mathrm{H}-8), 7.64$ (dd, $1 \mathrm{H}, J=8.4$ and $3.6 \mathrm{~Hz}, \mathrm{H}-7)$. LC/MS: $250(\mathrm{M}+\mathrm{H})$; Anal. Calcd. for $\mathrm{C}_{9} \mathrm{H}_{4} \mathrm{~N}_{5} \mathrm{O}_{2} \mathrm{Cl}: \mathrm{C}, 43.31 ; \mathrm{H}, 1.61 ; \mathrm{N}, 28.06 ; \mathrm{Cl}, 14.20$. Found $\mathrm{C}, 43.66 ; \mathrm{H}, 1.52 ; \mathrm{N}, 27.79 ; \mathrm{Cl}$, 14.01 .

1-Acetyl-4-chloro-1H-triazolo[4,5-g]quinoline (13). Compound 6 was suspended in acetic anhydride $(10 \mathrm{~mL})$ and the mixture heated at $90^{\circ} \mathrm{C}$ for $3 \mathrm{~h}$ under stirring. Then the excess of solvent was removed in vacuo to give a residue that taken up with diethyl ether gave crystals of 13 (0.16 g, 69\% yield), mp 201-203 ${ }^{\circ} \mathrm{C}$. IR ( $\left.\mathrm{cm}^{-1}\right): 1724,1608$. UV (nm): $\lambda_{\max } 209,225,253,285$, 297, 310, 316, 347, 364. ${ }^{1} \mathrm{H}-\mathrm{NMR}\left(\mathrm{DMSO}_{6}\right): \delta 9.17$ (d, 1H, $\left.J=3.8 \mathrm{~Hz}, \mathrm{H}-6\right), 8.84-8.80$ (m, 2H, H-8 + H-9), 7.76 (dd, $1 \mathrm{H}, J=8.4$ and $3.8 \mathrm{~Hz}, \mathrm{H}-7), 3.01$ (s, 3H, $\mathrm{CH}_{3}$ ). ${ }^{13} \mathrm{C}-\mathrm{NMR}$ (DMSO$\mathrm{d}_{6}$ ): $\delta 169.36(\mathrm{~s}), 152.48$ (d), 143.73 (s), 140.23 (s), 137.78 (d), 130.15 (s), 128.40 (s), 123.17 (d), 122.86 (s), 110.38 (d), 23.22 (q). MS M/Z 248, $246\left(\mathrm{M}^{+}\right)$. Anal. Calcd. for $\mathrm{C}_{11} \mathrm{H}_{7} \mathrm{~N}_{4} \mathrm{OCl}$ : C, 53.56; H, 2.86; N, 22.71; Cl, 14.37. Found C, 53.42; H, 3.01; N, 22.40, Cl, 14.11.

[4-Chloro-3H-triazolo[4,5-g]quinolin-3-yl]acetonitrile (14) and [4-chloro-1H-triazolo[4,5g]quinolin-1-yl]acetonitrile (15). Compound 6 (1 g, $4.9 \mathrm{mmol})$ was dissolved in dry dimethylformamide $(5 \mathrm{~mL})$ and added of $\mathrm{KOH}$ pellets $(0.31 \mathrm{~g}, 5.5 \mathrm{mmol})$. Then the mixture was kept under stirring at room temperature until $\mathrm{KOH}$ was completely dissolved. To this solution acetonitrile $(0.84 \mathrm{~g}, 11 \mathrm{mmol})$ was added dropwise and the mixture heated at $120-130^{\circ} \mathrm{C}$ under stirring for $22 \mathrm{~h}$. On cooling, the reaction mixture was poured onto $150 \mathrm{~mL}$ of crushed ice. A crude solid was collected, washed with water and eventually dried in an oven to be rechromatographed on silica gel column eluting with a mixture of diethyl ether acetone in the ratio of 9:1. Compound 14 was the fast mobile and came off first: $0.30 \mathrm{~g}$ (28\% yield), mp 201$203^{\circ} \mathrm{C}$, TLC (diethyl ether acetone 8:2): $\mathrm{R}_{\mathrm{f}} 0.84$. IR $\left(\mathrm{cm}^{-1}\right): 2230,1681,1625$. UV (nm): $\lambda_{\max }$ 224, 295, 307, 317, 348, 367. ${ }^{1} \mathrm{H}-\mathrm{NMR}\left(\mathrm{DMSO}_{-} \mathrm{d}_{6}\right): \delta 9.18(\mathrm{~d}, 1 \mathrm{H}, J=4.0 \mathrm{~Hz}, \mathrm{H}-6), 8.94(\mathrm{~s}, 1 \mathrm{H}$, $\mathrm{H}-9), 8.72(\mathrm{~d}, 1 \mathrm{H}, J=8.6 \mathrm{~Hz}, \mathrm{H}-8), 7.69$ (dd, $1 \mathrm{H}, J=8.6$ e $4.0 \mathrm{~Hz}, \mathrm{H}-7), 6.47\left(\mathrm{~s}, 2 \mathrm{H}, \mathrm{CH}_{2}\right) ;{ }^{13} \mathrm{C}-$ NMR (DMSO-d $)_{\text {) }}$ $\delta 153.89$ (d), 144.37 (s), 141.87 (s), 138.44 (d), 129.87 (s), 126.18 (s), 121.36 (d), 118.07 (d), 115.68 (s), 111.74 (s), 37.99 (t); MS M/Z 245, $243\left(\mathrm{M}^{+}\right)$. Anal. Calcd. for $\mathrm{C}_{11} \mathrm{H}_{6} \mathrm{~N}_{5} \mathrm{Cl}$ : C, 54.22; H, 2.48; N, 28.74; Cl, 14.55. Found C, 53.89; H, 2.71; N, 28.98, Cl, 14.22. followed by compound 1) $\left(0.38 \mathrm{~g}, 32 \%\right.$ yield), mp $254-256^{\circ} \mathrm{C}$, TLC (diethyl ether acetone 8:2): $\mathrm{R}_{\mathrm{f}}$ 0.70. IR ( $\left.\mathrm{cm}^{-1}\right): 2220,1683,1623$. UV (nm): $\lambda_{\max } 219,298,311,332,346,363$. ${ }^{1} \mathrm{H}-\mathrm{NMR}$ (DMSO-d $\left.)_{6}\right): \delta 9.13(\mathrm{~d}, 1 \mathrm{H}, J=4.0 \mathrm{~Hz}, \mathrm{H}-6), 8.68$ (d, 1H, $\left.J=8.6 \mathrm{~Hz}, \mathrm{H}-8\right), 8.58$ (s, 1H, H-9), $7.72(\mathrm{dd}, 1 \mathrm{H}, J=8.6$ e $4.0 \mathrm{~Hz}, \mathrm{H}-7), 6.39\left(\mathrm{~s}, 2 \mathrm{H}, \mathrm{CH}_{2}\right) ;{ }^{13} \mathrm{C}-\mathrm{NMR}\left(\mathrm{DMSO}_{6}\right): \delta 152.20(\mathrm{~d})$, 
143.55 (s), 139.42 (s), 137.34 (d), 131.14 (s), 128.81 (s), 122.70 (d), 114.88 (s), 111.74 (s), 106.23 (d), 36.33 (t); MS M/Z 245, $243\left(\mathrm{M}^{+}\right)$. Anal. Calcd. for $\mathrm{C}_{11} \mathrm{H}_{6} \mathrm{~N}_{5} \mathrm{Cl}: \mathrm{C}, 54.22 ; \mathrm{H}, 2.48$; N, 28.74; Cl, 14.55. Found C, 54.56; H, 2.30; N, 29.06, Cl, 14.77.

\section{References}

1. Fries, K.; Guterbock, H.; Kuhn, H. Liebigs Ann. Chem. 1934, 511, 213.

2. Slater, R.H. J. Chem. Soc. 1932, 2196.

3. Sanna, P.; Carta, A.; Paglietti, G. Heterocycles 2000, 53, 423.

4. Ferlin, M.G.; Castagliuolo, I.; Chiarelotto, G. J. Heterocyclic Chem. 2002, 39, 631.

5. Nuvole, A.; Sanna, P.; Paglietti, G.; Juliano, C.; Cappucinelli, P. Il Farmaco 1989, 44, 619.

6. Sanna, P.; Carta, A.; Paglietti, G.; Zanetti, S.; Fadda, G. Il Farmaco 1992, 47, 1001.

7. Sanna, P.; Sequi, P.A.; Paglietti, G. Il Farmaco 1995, 50, 47.

8. Hudlicky, M. Reductions in Organic Chemistry; Ellis Horwood Ltd: Chichester 1984, p 58 and references cited therein.

9. Carta, A.; Sanna, P.; Paglietti, G.; Sparatore, F. Heterocycles 2001, 55, 1133. 